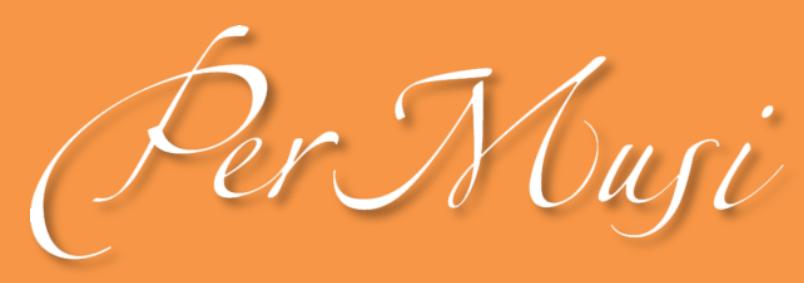

eISSN 2317-6377

\title{
José Maurício Nunes Garcia: um mulato civilizado na Primeira República Brasileira
}

\author{
Luiz Guilherme Goldberg \\ https://orcid.org/0000-0001-5991-4761 \\ Universidade Federal de Pelotas, Centro de Artes \\ guilherme_goldberg@hotmail.com
}

SCIENTIFIC ARTICLE

Submitted date: 19 may 2019

Final approval date: 17 aug 2019

Resumo: A localização do manuscrito autógrafo de Alberto Nepomuceno da sua transcrição da Missa Festiva, de José Maurício Nunes Garcia, trouxe à luz uma informação inédita até aquele momento. Uma vez que tal partitura não constava no Alberto Nepomuceno Catálogo Geral (Corrêa, 1985; 1996), tal identificação promoveu o retorno à investigação sobre a significação de José Maurício Nunes Garcia no estabelecimento de uma identidade musical pela Primeira República brasileira. Este é o objetivo deste artigo.

Palavras-chave: José Maurício Nunes Garcia; Alberto Nepomuceno; Missa Festiva ou de Santa Cecília; Belle Époque Musical; História da música brasileira.

\section{JOSÉ MAURÍCIO NUNES GARCÍA: A CIVILIZED MULATTO IN THE FIRST BRAZILIAN REPUBLIC}

Abstract: The find of the autograph manuscript of Alberto Nepomuceno's transcription of the Festive Mass, by José Maurício Nunes Garcia, brought to light information previously unknown. Since such score was not at Alberto Nepomuceno's General Catalog (Corrêa, 1985, 1996), this identification promoted the return to the investigation of the meaning of José Maurício Nunes Garcia in the establishment of a musical identity by the First Brazilian Republic. This is the aim of this paper.

Keywords: José Maurício Nunes Garcia; Alberto Nepomuceno; Festive Mass or of Santa Cecília; Musical Belle Époque; Brazilian Music History. 


\section{José Maurício Nunes Garcia:}

\section{um mulato civilizado na Primeira República}

Luiz Guilherme Goldberg, Universidade Federal de Pelotas, guilherme_goldberg@hotmail.com

\section{Introdução}

A Primeira República brasileira, recém proclamada, necessitava criar símbolos e ícones que a legitimasse, que a consolidasse como o passo adiante frente à monarquia e ao atraso a ela associado. Essa herança imperial fora registrada por Oscar Guanabarino, em 1896, quando de uma análise sobre o teatro no país. Para ele,

A má politica e a pessima administração publica do imperio, o abandono do ensino e a invasão de todos os ramos do governo pelos bachareis formados pela politicagem trouxeram a suffocação do principio da nossa litteratura; e basta lembrar que o imperio legou á Republica doze milhões de analphabetos para reconhecer a impossibilidade de fazer medrar a litteratura em semelhante terreno.

A esse vergonhoso numero de analphabetos junte-se a carestia do livro e ahi teremos a causa da paralysia. (O Paiz 25 fev. 1896, 2)

Assim, tem-se que o progresso e a civilização estavam entre os objetivos da República, embora num ambiente em que prevaleciam teorias evolucionistas que pregavam a inviabilidade da nação brasileira devido a inerente contradição entre civilidade e mestiçagem.

Nesse cenário, um dos braços institucionais para a doutrinação e criação de uma identidade cultural nacional civilizada materializava-se no Instituto Nacional de Música, que forneceria as diretrizes para a educação musical e sensibilização artística das almas pátrias. As premissas para essa tarefa foram registradas pelo primeiro diretor da instituição, Leopoldo Miguez, em seu relatório Organização dos conservatórios de música na Europa (Vermes 2004) e levadas adiante por Alberto Nepomuceno.

A dimensão do projeto emanado pelo Instituto Nacional de Música pode ser diagnosticada se atentarmos, por exemplo, a duas atividades que demonstram a abrangência de suas premissas. Se, de um lado, em inícios do século XX há registros de correspondências entre Nepomuceno e Coelho Netto, em Campinas, Félix de Otero, em São Paulo, Silvio Deolindo Fróis, em Salvador e Euclides Fonseca, em Recife, quanto à descentralização do movimento artístico e ampliação da ação estética (Pereira 2007, 164), de outro, egressos do Instituto Nacional de Música associaram-se no Centro de Cultura Artística do Rio Grande do Sul com o mesmo intuito, que resultou na fundação de 15 conservatórios de música (Goldberg; Nogueira 2009). 
Enquanto a necessidade da criação de símbolos republicanos capazes de criar significação popular tem, no plano cívico, o heroico Joaquim José da Silva Xavier, conhecido como Tiradentes, (Carvalho 1990), no cultural, Visconde de Taunay amplificava o censo relativo a dois "artistas máximos" para a música brasileira: José Maurício Nunes Garcia e Antônio Carlos Gomes (Taunay [19-?]a).

Importante aqui salientar que esse processo de construção do mito José Maurício Nunes Garcia seria mais um componente ideológico fundamental, pois aproximaria dois elementos caros na pretensa elaboração de uma identidade nacional: o germanismo e o mulatismo.

Que os dois primeiros diretores do Instituto Nacional de Música, Leopoldo Miguez e Alberto Nepomuceno, estavam engajados no projeto do Visconde de Taunay quanto a elevação de José Maurício Nunes Garcia a um dos ícones da música brasileira não é novidade; que Nepomuceno tenha revisado e transcrito algumas obras sacras desse compositor, como atesta seu Catálogo Geral (Corrêa 1985; 1996), muito menos. Mas a localização, em 2003, do manuscrito autógrafo de Nepomuceno da Missa Festiva de José Maurício trouxe interesse em revisitar o contexto no qual tais atividades ocorreram.

\section{Alberto Nepomuceno e a obra de José Maurício}

No ano de 2003, alertado pela musicóloga Carla Bromberg sobre a possível localização de um manuscrito autógrafo de Alberto Nepomuceno da Missa Festiva do padre José Maurício Nunes Garcia (Fig. 1), o interesse foi imediato. Tal curiosidade deu-se, primeiramente, devido essa Missa receber, nas duas edições do Alberto Nepomuceno Catálogo Geral, somente a menção "na inauguração da Igreja da Candelária, rege a Missa festiva de padre José Maurício" (1767-1830) (Corrêa 1996, 12), mais adiante identificada como a Missa de Santa Cecília (Corrêa 1996, 18). Mais interessante ficou quando, na seção dedicada às obras de José Maurício Nunes Garcia revisadas por Nepomuceno, sequer havia menção a Missa Festiva ou de Santa Cecília. Nela há referência à revisão de 11 obras do padre, entre as quais a Missa em si bemol, de 1801; a Missa (Pequena), composta em 1809, para o dia de São Pedro de Alcântara; e a Missa de Réquiem, concebida em 1816 (Corrêa 1996, 54). 


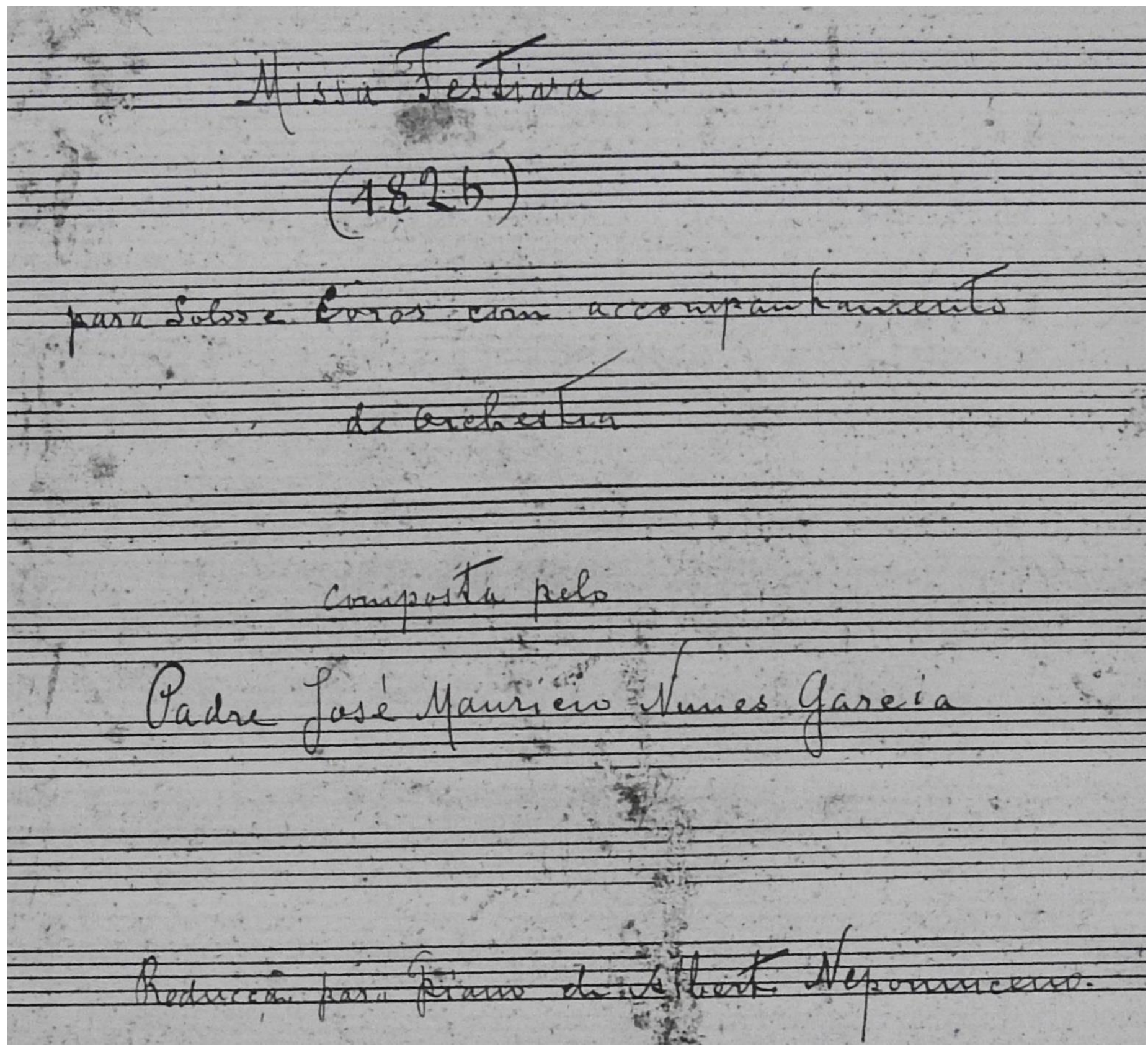

Figura 1 - Frontispício MS Alberto Nepomuceno

Outra referência sobre o vínculo de Nepomuceno com a Missa Festiva e/ou de Santa Cecilia pode ser encontrada no aparato crítico de Cleofe Person de Mattos para a sua publicação pela FUNARTE. De acordo com esta autora, "sob a direção de Alberto Nepomuceno foi então ouvida [a Missa Festiva], mas não identificada à sempre citada Missa de Santa Cecília, [...]" durante a inauguração da igreja da Candelária. (Mattos 1984, 17).

Mesmo que apoiado no Alberto Nepomuceno Catálogo Geral, Avelino Pereira dá um passo adiante em relação às referências anteriores ao observar que, "restaurada e impressa pela Casa Bevilacqua, a Missa festiva do padre compositor, hoje conhecida como Missa de Santa Cecília, seria regida por Nepomuceno, na inauguração da Candelária" (Pereira 2007, 131), apesar de não deixar claramente registrada a autoria de tal restauração e responsabilidade pela publicação.

Todavia, embora essa Missa seja encontrada em poucas referências, provavelmente pela ênfase na abordagem nacionalista que se dá a respeito desse compositor, a ocupação de Nepomuceno com as missas de José Maurício representou um importante aspecto de sua produção. Tal pode ser observado em 
Appleby, para quem "com a colaboração do Visconde de Taunay, ele [Nepomuceno] preparou performances da Missa de Requiem e da Missa em Si bemol, de José Maurício Nunes Garcia, composições que não se ouviam no Brasil há muitos anos"11 (Appleby 1983, 89).

Assim, com as informações restringindo-se prioritariamente à regência da obra e uma inferência da publicação de sua restauração, a localização de uma partitura manuscrita com a indicação Reducção para piano de Alberto Nepomuceno, mostrou-se um importante achado, indicando que sua atividade tinha ido além das já referidas. Em suma, tratava-se de algo novo, que poderia reforçar ou trazer novos conhecimentos sobre as relações de Alberto Nepomuceno e a música sacra no Brasil ${ }^{2}$.

Lembramo-nos que, nos tempos do regimen decahido, o Sr. Visconde de Taunay, um artista e talvez um crente, teve a coragem de levar até ao seio do parlamento o seu enthusiasmo pelas soberbas composições sacras do Padre José Maurício, e dispendeu o melhor dos seus esforços e sua poderosa eloquencia para obter uma pequena somma com que se podesse salvar das traças destruidoras o precioso archivo das musicas do grande artista nacional. $\mathrm{O}$ parlamento, porém, regateou-lhe as migalhas pedidas sem comprehender que era uma parcella da honra e da gloria da propria patria, que servia de pasto aos vermes roedores.

Talvez seja ainda tempo de vir em socorro desse archivo de valor e, ou pedindo-a ao Congresso da Republica, ou procurando obte-la por meio de festas, doações, etc., a Sociedade que se fundar póde prestar immediatamente esse serviço valiosissimo, duplamente necessario, de restituir á arte brasileira e ás solemnidades da Igreja as bellas concepções musicaes do Padre José Mauricio (Jornal Do Commercio 7 out. 1895, 2).

No excerto acima, José Rodrigues Barbosa, redator do Jornal do Commercio e articulista da campanha de restauração da música sacra no Brasil, manifesta-se sobre a pregação iniciada anos antes pelo Visconde de Taunay em prol da música do padre José Maurício Nunes Garcia, "grande glória brasileira" e um dos nossos "artistas máximos". A partir deste momento, a voz solitária do Visconde encontraria um reforço de grande expressão, que aproximaria seus projetos através da fusão dos dois movimentos em uma mesma campanha: um genérico, a restauração da música sacra; outro específico, o resgate artístico do padre José Maurício.

Importante manter a perspectiva do que significava a figura de Rodrigues Barbosa durante esse momento histórico: além de ser o redator de um dos mais importantes jornais diários do Rio de Janeiro, pertencia ao círculo dos membros diretivos do Instituto Nacional de Música, tendo sido nomeado membro honorário dessa instituição em 25 de maio de 1903 (PEREIRA 2007, 455).

1 With the collaboration of the Viscount of Taunay, he [Nepomuceno] prepared performances of the Requiem Mass and the Mass in B Flat of José Maurício Nunes Garcia, works that had not been heard in Brazil in many years. (Appleby, 1983: 89)

${ }^{2}$ Como alertado por Vermes (2000), seu envolvimento ocorreu em duas direções simultaneamente: de um lado, seu engajamento na campanha de restauração da música sacra brasileira iniciada em 1895 por Rodrigues Barbosa; de outro, seu comprometimento com o ideal do Visconde de Taunay de recuperação e publicação das obras do padre José Maurício Nunes Garcia. 
A resposta do amigo Nepomuceno a esse chamado também foi quase imediata, sendo sua adesão e andamento de trabalho reconhecidos pelo Visconde de Taunay, fazendo noticiar no Jornal do Commercio, de 2 de abril de 1896, que

O maestro Nepomuceno, cujo primoroso e educado talento e cujas largas aptidões vão sendo felizmente devidamente aquilatados, abalançou-se a tarefa da mais alta benemerência.

Resolveu reduzir para piano e harmonium o admirável Réquiem de José Mauricio, que Neukomm não duvidava collocar ao lado do de Mozart, e tem a obra quase concluída (Jornal do Commercio 2 abr. 1896, 2).

Por sua vez, Nepomuceno manifestou a sua admiração ao padre compositor prevendo "[...] não tarda[r] a aurora do dia em que as obras primas do Mestre sejam publicadas para que não só os brazileiros mas a humanidade possam receber o legado do patrimônio o que elle deixou." (Nepomuceno apud Figueiredo $2000,1)$.

Seu empenho nesse sentido foi tanto que em junho de 1896 já havia concluído o trabalho na Missa de Réquiem, fazendo com que finalmente o projeto de Taunay, iniciado em 1887, obtivesse algum êxito. Um projeto iniciado há quase uma década, que não contou com apoio oficial - vale lembrar que Taunay fora "acusado, em plena Câmara, de estar fazendo os senhores deputados perderem o seu precioso tempo por causa de um rabequista." (Luiz Heitor apud Kiefer, 1982: 57-58) - , dava seus primeiros frutos.

Com uma forte campanha de subscrições no Jornal do Commercio, que durou todo o ano de 1896 e parte do ano seguinte, as adesões chegavam de várias partes do país, como Porto Alegre, Curitiba, Juiz de Fora, além do Rio de Janeiro. Assim, não sem muito esforço, finalmente uma batalha estava vencida: a Missa de Réquiem, na redução de Alberto Nepomuceno, foi publicada em 1897.

Na mesma época, Alberto Nepomuceno já havia quase concluído trabalho semelhante com a Missa em si bemol, de 1801. Desta vez, a publicação se mostrou menos árdua e, em 24 de janeiro de 1898, o Visconde de Taunay fazia publicar no Jornal do Commercio uma Carta Aberta a Nepomuceno, onde expressa toda a sua gratidão.

O senhor, insigne maestro, prestou grande, immenso serviço a todos nós, ao Brazil, á Arte, tornando possivel a publicação dessa despretenciosa e valiosissima obra do nosso amado José Mauricio.

Mil parabens, um aperto de ambas as mãos, mais que isto, enthusiastico e estreito abraço dado com a exultação de toda a minh'alma, ainda vibrante no meio das suas tristezas e conturbações (Jornal Do Commercio 24 jan. 1898, 2).

Desta vez, além da redução para órgão ou harmônio, Nepomuceno também realizou a sua revisão e orquestração. A importância e significação atribuídas a essa Missa fez com que fosse a obra mauriciana executada tanto na celebração da Sagração da Igreja da Candelária, no Rio de Janeiro, em 26 de junho de 1898, quanto na missa do domingo seguinte, 3 de julho. Trata-se de um marco para a República, que será retomado mais adiante. 
A próxima obra de José Maurício Nunes Garcia que Alberto Nepomuceno se dedicou foi a Missa Festiva ou de Santa Cecília (Fig. 2), reduzida para piano e executada durante a inauguração da Igreja da Candelária, em 10 de julho de 1898, que será abordada com mais detalhe na seção seguinte.

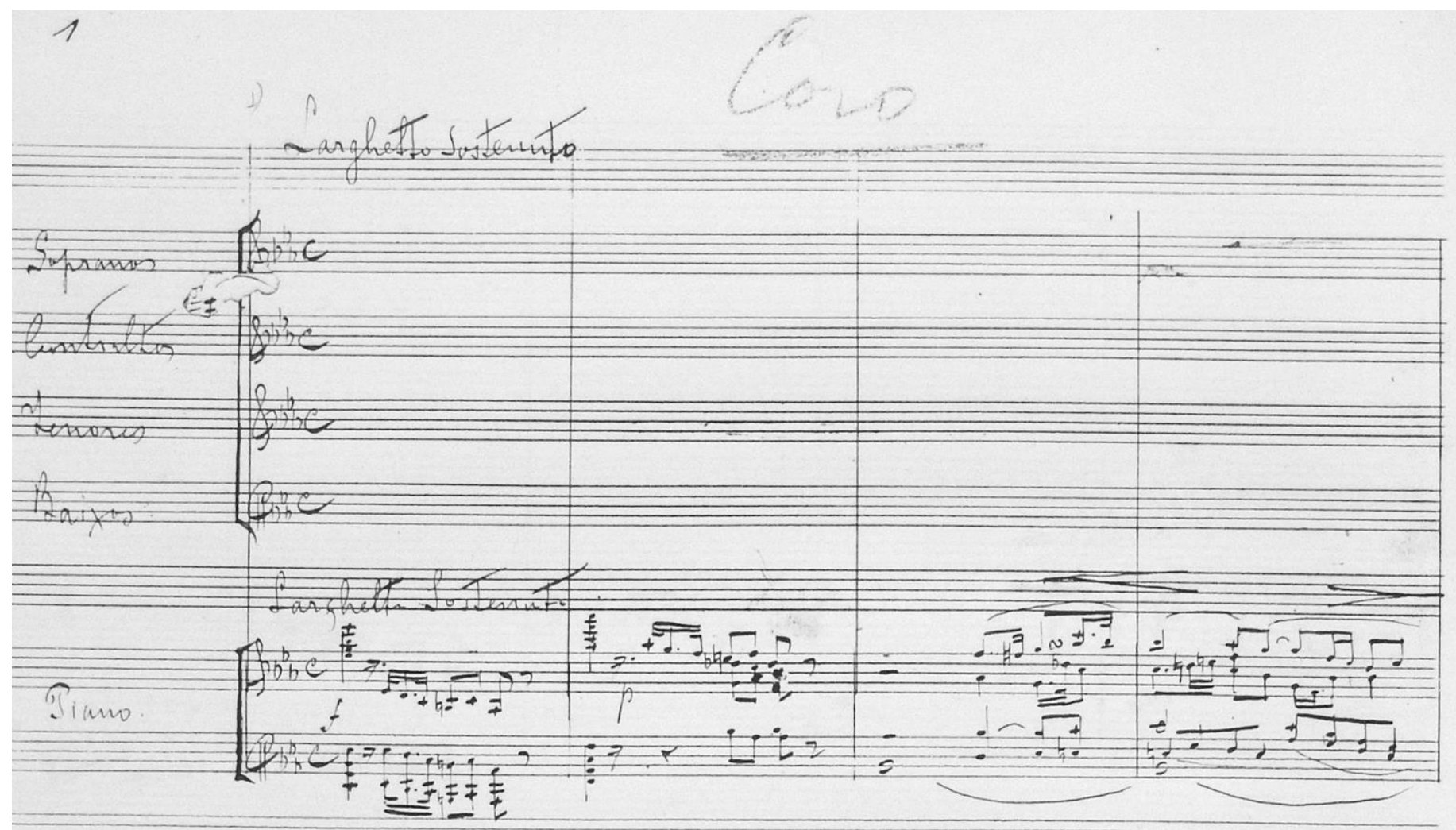

Figura 2 - Incipt MS Alberto Nepomuceno

Com base nas informações acima expostas, apresenta-se, na tabela 1, a relação atualizada das obras de José Maurício trabalhadas por Nepomuceno. Tomando-se o Alberto Nepomuceno Catálogo Geral como fonte, procedeu-se a alteração do registro do ano em que ocorreram a revisão e a orquestração da Missa em si bemol, de 1899 para 1898, bem como efetuou-se o acréscimo da redução para piano da Missa Festiva ou de Santa Cecilia.

Tabela 1 - Obras de José Maurício Nunes Garcia revisadas por Alberto Nepomuceno

\begin{tabular}{|c|c|c|}
\hline Obra & Tarefa & Data \\
\hline Tantum ergo & Sem informação & Sem data \\
\hline O sacrum convivium & Revisão & 1896 \\
\hline Missa de Réquiem & Redução para órgão e/ou harmônio & 1897 \\
\hline Missa em Si Bemol & $\begin{array}{l}\text { Redução para órgão e/ou harmônio } \\
\text { Revisão e orquestração }\end{array}$ & 1898 \\
\hline Missa Festiva ou de Santa Cecília & Redução para piano & 1898 \\
\hline Ave Maris Stella & Revisão & 1899 \\
\hline Credo abreviado & Revisão & 1899 \\
\hline Ecce sacerdos & Revisão & 1899 \\
\hline Graduale sequentia do Espírito Santo & Revisão & 1899 \\
\hline Missa (Pequena) & Revisão & 1899 \\
\hline $\begin{array}{l}\text { Salmos } 1,2 \text { e } 3 \text { (para as vésperas das Dores de } \\
\text { Nossa Senhora) }\end{array}$ & Revisão & 1899 \\
\hline Sinfonia Tempestade & Particella & 1899 \\
\hline
\end{tabular}


Como antecipado na introdução deste artigo, o interesse pelas composições do padre José Maurício Nunes Garcia estava fundamentado não só em seu valor artístico, mas também em uma demanda ideológica: era uma questão de patriotismo. Assim o Visconde de Taunay se manifestava em 1897.

Tratava-se ahí uma questão de patriotismo, de arte e ao mesmo tempo de interesse de classe, mostrando-se á evidencia que há muito, possuia o nosso clero quem podia hombrear com os maiores mestres na musica sacra (Jornal do Commercio 9 jan. 1897, 2).

O discurso patriótico é encontrado com frequência nas publicações da imprensa periódica do período, atendendo a sua vocação doutrinadora e orientadora do povo, de acordo com a concepção de Guanabarino (O Paiz 25 fev. 1896, 2). É preciso atentar que

A Primeira República, neste momento, está empenhada em uma política de criação de uma identidade nacional, empenhada em uma política de transformação e afirmação do Brasil como uma nação civilizada, sendo que, para isso, é necessário a criação de um patrimônio artístico e cultural que represente esse desenvolvimento tão almejado (Carvalho 2003, 7).

A dimensão dessa tarefa pode ser mais bem avaliada se levarmos em consideração que era moeda corrente a crença na inviabilidade de uma nação civilizada nos trópicos e, além disso, mestiça. (Odália apud Reis 2002 , 94). O consumo de teorias cientificistas, deterministas, positivistas formava um substrato que justificava esta crença ${ }^{3}$. Assim, considerando-se que o patriotismo seria sinônimo de uma identidade nacional, era preciso equacionar a questão civilizatória com o mulatismo no Brasil.

Sob esse aspecto, José Maurício era o exemplo da viabilidade da civilização brasileira, unindo-se nele o

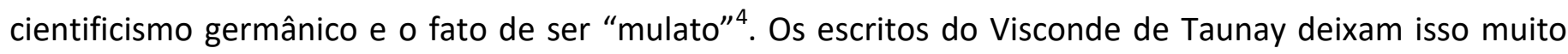
claro, além de também evidenciarem o antigo conflito entre as escolas italiana e alemã.

Essa disputa entre as escolas latina e germânica representa a ideação que moldava os discursos nacionalistas, num exercício de apropriações que demonstravam o caminho para o progresso e a civilização. Tal posicionamento é demonstrado pelo Visconde de Taunay, ao associar esse confronto às disputas entre Marcos Portugal (1762-1830) e José Maurício.

Nos choques, porém, contínuos, de todos os momentos, entre essas duas eminentes personalidades artísticas, [...] havia muito mais - o fundamental antagonismo de duas possantes escolas de tendencias e feitura absolutamente discordantes, com objetivos diversos, buscando cada qual supplantar outra; a italiana toda ella melodica e flacida de posse então do primeiro lugar, em que dominava senhora absoluta de quasi todos os paizes cultos, a alleman, firmada na harmonia e na severidade scientifica, disputando-lhe a supremacia e preeminencia, que afinal conseguiu, por ter do seu lado a verdade e a legitima elevação intellectual e esthetica. (Taunay [19-?]b, 88-89)

\footnotetext{
${ }^{3}$ Sobre esse assunto, ver Schwarcz, Lilia Moritz. 1993. O espetáculo das raças: cientistas, instituições $e$ questão racial no Brasil - 1870-1930. São Paulo: Companhia das Letras.

${ }^{4}$ Este tema será retomado no último tópico deste artigo.
} 
Assim, a vinculação de José Maurício à escola alemã era, pois, necessária e plenamente justificada. O mito José Maurício Nunes Garcia, na acepção do Visconde de Taunay, demonstraria a viabilidade nacional do Brasil e, mesmo que excepcionalmente, o valor de seu povo mestiço.

Era a grandiosa escola allemã dos Haendel, Mozart, Haydn e Beethoven apertando em seus braços o inspirado discipulo, o pobre e modesto, mas immorredouro mestiço brasileiro, neto de uma negra da Costa d'Africa reduzida á escravidão pela maldade dos homens! (Taunay [19-?]a, 10)

Dessa forma, conclui-se que, para estar engajado no mundo civilizado, a preservação das obras do padre José Maurício Nunes Garcia seria uma tarefa de vital importância para a afirmação de uma identidade cultural brasileira. Um "mulato", formado na escola alemã, cujo valor fora reconhecido por Sigismund Neukomm (1778-1858), seria assim alçado à esfera dos heróis nacionais.

Mas, paradoxalmente, também as obras compostas após 1811, quando a influência da escola italiana tornou-se mais forte, receberam atenção. Um exemplo marcante é a Missa Festiva ou de Santa Cecília, executada na inauguração da Candelária, uma imensa festividade política e religiosa.

\section{A Missa Festiva ou de Santa Cecília}

O ponto culminante do movimento de resgate artístico do padre José Maurício Nunes Garcia pode ser identificado num dos mais significativos eventos da história republicana do Rio de Janeiro: a inauguração da Igreja da Candelária. Tratava-se da ocasião ideal para que as obras de José Maurício fossem apresentadas com toda a pompa e circunstância.

Quando, em 14 de fevereiro de 1898, o Visconde de Taunay foi convidado, pelo Provedor da Irmandade da Candelária, para a direção artística das festividades de inauguração da Igreja da Candelária ${ }^{5}$, a orientação determinava expressamente que ali deveriam ser executadas composições sacras do padre José Maurício. Para isso, estava Taunay também autorizado a imprimi-las.

Tal responsabilidade foi dividida com Alberto Nepomuceno, a quem o Visconde delegou os poderes da incumbência da realização, resguardando para si "a parte de interferencia necessaria, afim que todos os seus intuitos e vistas sejão preenchidos em regra." (Jornal do Commercio 20 fev. 1898, 2).

As festividades da Igreja da Candelária mostraram-se de uma pompa nunca vista. Conforme relato do Visconde de Taunay, a respeito da festa do dia 10 de julho,

Foi a consagração da Candelaria uma das mais grandiosas cerimonias que tem presenciado o Rio de Janeiro. Impossivel mais pompa, mais significencia, a par de mais profundo respeito e absoluta ordem, de maneira que tudo se congregou n'um conjunto de inexcedivel realce e significação. [...].

\footnotetext{
${ }^{5}$ Existem duas referências sobre a data da inauguração da Igreja da Candelária: 3 de julho, segundo Sérgio Alvim Corrêa e Avelino Pereira; e 10 de julho, conforme relato do Visconde de Taunay. Tal confusão pode ser desfeita na pesquisa aos jornais da época, estando as datas assim definidas: em 26 de julho, durante a sagração da Candelária, Nepomuceno rege a Missa em si bemol de José Maurício; a 3 de julho, novamente é executada a Missa em si bemol; somente em 10 de julho, durante a inauguração da Candelária, foi realizada a Missa Festiva ou de Santa Cecilia.
} 
A musica, regida pelo illustre maestro Alberto Nepomuceno, esteve á altura de tão extraordinaria funcção religiosa. A Missa festiva de 1826, da lavra do padre José Maurício, embora desigual em suas partes componentes, é de grande e largo folego, como só a poderia escrever autor do estro, valor e sciencia do nosso immortal patriota. Os concertantes e córos tem bellezas raras e mostra-se a instrumentação da maior abundância e vigor, cheia de intuitos muito além da época em que foi feita, trechos de verdadeiro wagnerismo, tal a possança daquelle genio brasileiro!

Em contraposição, os sólos são verdadeiras arias italianas no gosto então dominante, amaneirados, de feição essencialmente dramatica e tendente a effeitos um tanto corriqueiros; com o cunho, porém, sempre de um grande mestre. [...]

A regencia do incansavel maestro Nepomuceno salientou-se pela extrema e nunca assaz louvada correcção.

Nem uma só vez se ouviu o tão habitual, desrespeitoso e incommodo bater da batuta na estante.

Parecia que, naquelle côro de tantos cantores e instrumentistas não figurava a personalidade do regente da orchestra, quando, entretanto, a todo o instante o seu poder se accentuava imperioso, magistral, na direcção das massas coraes e instrumentaes, que não claudicaram um momento, apezar das difficuldades da partitura. Extraordinario o esfôrço que o proficiente e inspirado artista desenvolveu! Impossivel fôra na realidade ter entregue a melhores mãos a missão tão ardua de que se viu incumbido. (Taunay [19-?]a, 65-67)

A declaração de Taunay encontra guarida também nos periódicos Jornal do Commercio, Gazeta de Notícias, O Paiz, A Notícia, entre outros, que atestam a excepcionalidade do evento.

Inevitável salientar a contraposição realizada por Taunay entre os "trechos de verdadeiro wagnerismo" e as "verdadeiras árias italianas" presentes na obra. O denominador comum "verdadeiro" não deixa espaço para dúvidas, embora, para as "árias", o reforce com qualificativos pejorativos. É instigante observar o esforço intelectual de Taunay em associar a Missa Festiva de José Maurício a algum tipo de wagnerismo, uma vez que, enquanto aquela fora composta em 1826, as primeiras composições de Wagner que se tem registro datam somente de 1829 (Picard 2010). Tal postura associa-se ao que era considerado moderno no Brasil desse momento, compartilhando o mesmo ideal estético de, por exemplo, Leopoldo Miguez ou Alberto Nepomuceno.

De qualquer forma, apesar do êxito obtido durante as festividades da Candelária, o projeto idealizado pelo Visconde de Taunay, e assumido por Alberto Nepomuceno, parece não ter sido completado, uma vez que a expectativa da realização de uma luxuosa publicação, na Alemanha, não teria sido realizada. Nas pesquisas diárias nos jornais da época, até 25 janeiro de 1899, data da morte do Visconde de Taunay, nenhuma referência foi encontrada sobre essa publicação.

Reforçam essa possibilidade duas circunstâncias: a primeira, o fato de sua execução, na festividade da Candelária, ter sido realizada na versão orquestral, cuja partitura não foi localizada, mas sim a da redução para piano; a segunda, que a única publicação localizada restringe-se às partes do coro, gravada pela Casa 
Bevilacqua, chapa $n^{\circ} .3983$, portanto ainda em $1898^{6}$. Assim, até o presente momento, não foi localizada a publicação das partituras realizadas por Alberto Nepomuceno da Missa Festiva ou de Santa Cecília, tanto da redução para piano, quanto de alguma possível orquestração.

Com a morte do Visconde de Taunay, encerra-se uma campanha levada à frente com tanta paixão.

Para encerrar, um breve esclarecimento sobre o nome da Missa, se Festiva ou de Santa Cecília. Segundo Cleofe Person de Mattos (1984; 1996), ao não associar a partitura que tinha em mãos à Missa de Santa Cecília, o Visconde de Taunay teria Ihe atribuído, equivocadamente, a denominação Missa Festiva. No entanto, tal conclusão pode ser revista ao levar-se em consideração declaração do próprio Visconde.

Em matéria publicada em 27 de junho de 1898, no Jornal do Commercio, Taunay não só havia esclarecido sobre a existência das duas cópias da Missa, como também, em função da solenidade em que seria realizada, justificara a denominação "Festiva".

Na grande ceremonia, que se dará em julho, a longa Missa a executar-se ha de ser denominada Festiva, em mi bemol maior, e, como já sabemos, composta em 1826. Verificou-se que era uma das partituras que formão o volume emprestado, ha dias, pelo Instituto Historico e de que o Instituto Nacional de Musica tinha uma cópia, aproveitada agora pelo maestro Nepomuceno [...] (Jornal do Commercio 27 jun. 1898, 3).

\section{Um compositor mulato}

José Maurício Nunes Garcia tem sido tradicionalmente descrito como mulato. Entretanto, a divergência de informações entre algumas fontes possibilita o surgimento da hipótese desse compositor ter sido um negro descrito pelo filtro do branqueamento.

Embora haja, ao menos, duas imagens que sustentariam especulações étnicas, - seu retrato a óleo, pintado por seu filho José Maurício Nunes Garcia (Fig. 3); sua máscara mortuária, mandada extrair por Manuel de Araújo Porto-Alegre - , as fontes aqui utilizadas serão as documentais não iconográficas.

\footnotetext{
${ }^{6}$ A atribuição desta data foi possível graças à pesquisa da musicóloga Mercedes dos Reis Pequeno, sobre a impressão musical no Brasil. Enciclopédia da música brasileira: erudita, folclórica e popular. Org. Marcos Antônio Marcondes. 2 ed., rev. ampl. São Paulo: Art Editora, 1998.
} 


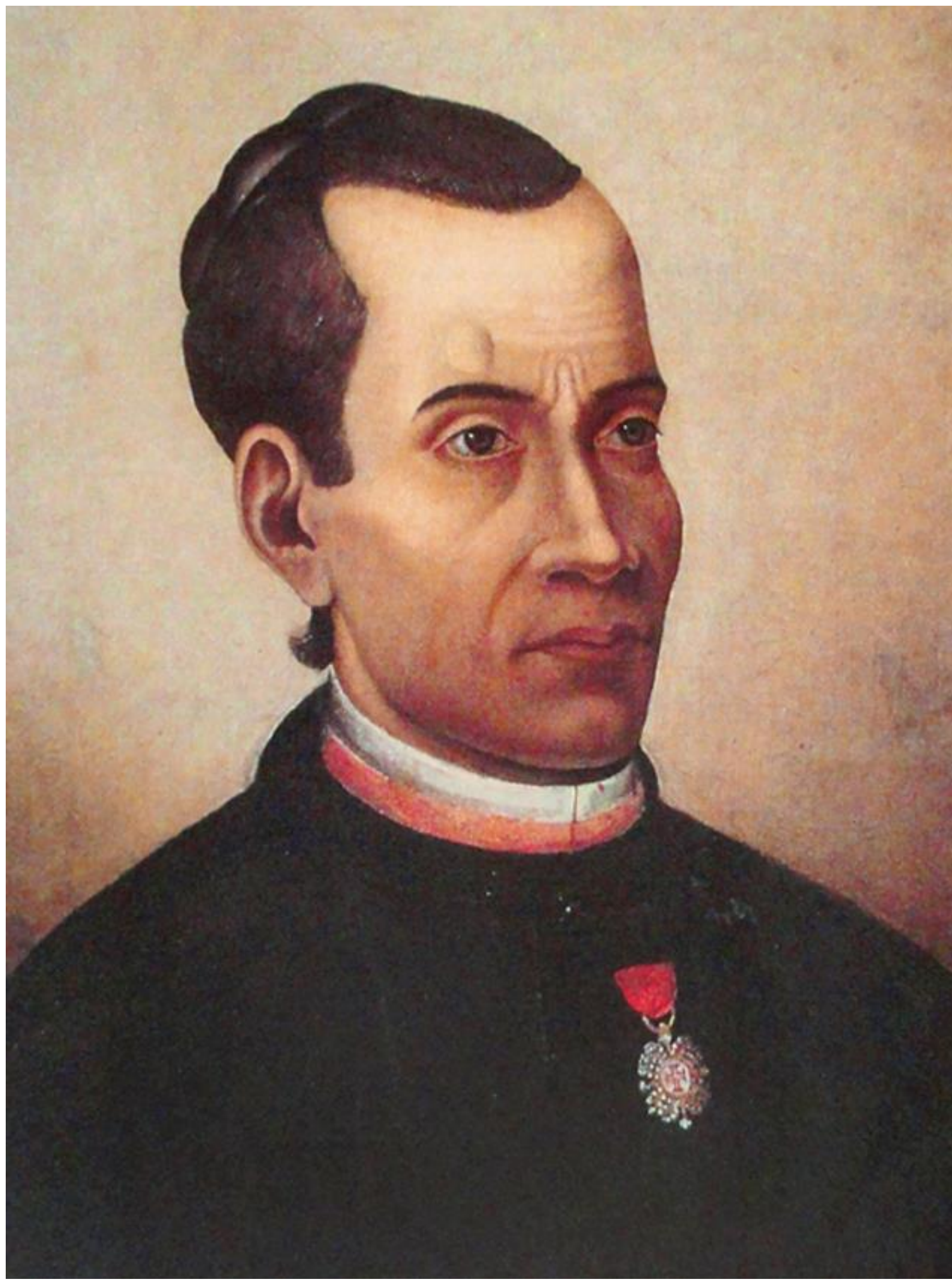

Figura 3 - Retrato a óleo de José Maurício Nunes Garcia, pintado por seu filho José Maurício Nunes Garcia. Acervo da Escola de Música da UFRJ, Rio de Janeiro. 
Mesmo que essas não sejam primárias, a hipótese que se apresenta leva em consideração descrições e interpretações que daquelas foram extraídas. Além disso, tratando-se de uma hipótese, não se pretende dar o assunto por concluído, mas sim trazer elementos para reflexão.

A primeira fonte documental é o texto Apontamentos sobre a vida e obras do Padre José Maurício Nunes Garcia, de Manuel de Araújo Porto-Alegre, primeiro biógrafo do compositor. Além de ser contemporâneo a José Maurício, Porto-Alegre foi "companheiro de estudos" de seu filho José Maurício Nunes Garcia e, como já mencionado, o responsável pela extração da máscara mortuária do compositor (Porto-Alegre 1856, 368).

Nessa publicação, Porto-Alegre registra a condição etnica de José Maurício em duas situações: na primeira, mesmo considerando o apoio irrestrito que o compositor recebia de D. João VI, refere-se ao incômodo que sua origem causava na côrte e, apesar disso, que o compositor era tolerado.

a despeito da sua côr mixtiça, era tolerado na côrte, n'essa côrte onde o auto de nascimento formava o maior merecimento do homem, dava direito a todas as sympathias, e onde o ser Brazileiro, e mormente mulato, bastavam para alienar de si todos os favores, e mesmo muitos direitos. (Porto-Alegre 1856, 360)

Na segunda, ao descrever as suas características físicas, informa que "as dimensões e saliencias osseas do seu todo, mostravam que havia sido de uma forte constituição. Tinha nos labios, na fórma do nariz, e na saliencia dos pomolos os caracteres da raça mixta" (Porto-Alegre 1856, 368).

Como pode ser observado, Manuel de Araújo Porto-Alegre retrata a etnicidade de José Maurício de três maneiras: de "côr mestiça"; de "raça mixta"; ou "mulato".

Sacramento Blake segue na mesma linha, mas, desta vez, através da reprodução de um trecho de carta do Visconde de Taunay, na qual relata a impressão deixada por José Maurício em Sigismund Neukomm ${ }^{7}$. Segundo ele, Neukomm teria afirmado que "Ninguem me lembra tanto o mestre, [...], como esse mulato genial" (Sacramento Blake 1899, 88).

Tais considerações encontram respaldo na cópia da certidão de casamento dos pais de José Maurício, em seu processo de habilitação à carreira sacerdotal, de genere ${ }^{8}$, transcrita por Cleofe Person de Mattos. Nela

\footnotetext{
${ }^{7}$ Carta do Sr. Dr. Escragnolle Taunay ao Sr. Dr. Goulart, publicada na Gazeta de Notícias do dia 27 de outubro de 1884.

${ }^{8} \mathrm{O}$ processo de genere, isto é, para a habilitação à carreira sacerdotal está prescrito detalhadamente no Regimento do Auditorio Ecclesiastico do Arcebispado da Bahia.
}

37. Querendo-se alguem ordenar de Ordens Menores, ou Sacras nos farà petição declarando seu nome, Pays, \& Avós, \& donde he natural, \& morador, \& que sciencia professa, \& que annos tem, para nos informarmos em segredo se tem as partes, $\&$ virtudes necessarias para ser clerigo, $\&$ achando-se o sufficiente lhe mandaremos fazer as diligencias necessarias pelo nosso Provisor que saõ as seguintes.

38. Ajuntaraõ com a petiçaõ que fizerem quando a apresentarem ao nosso Provisor sua sentença de genere corrente, \& o Provisor mandarà passar mandado de segredo ao Parocho do Ordinando para que secretamente se informe da limpeza de sangue, vida, \& costumes, \& do mais que ordenamos em nossas Constituiçoens no titulo do Sacramento da Ordem, \& que da informaçaõ que achar passe certidão no mesmo mandado jurada in verbo Sacerdotis, \& nomearà quatro, ou cinco testemunhas que deponhaõ na verdade o que na Certidaõ declarar. (Regimento do Auditorio Ecclesiastico do Arcebispado da Bahia. Titulo I, § II, Das diligencias que o nosso Provisor deve mandar fazer quando alguem se ordenar de Ordens Menores, \& Sacras, 1718: 11-12, grifo nosso). 
pode-se ler: "Recebeo em matrimonia a Apolinario Nunes Gracia, pardo forro $f^{\circ} n^{\text {al }}$ de Anna Correa do Desterro Crioula de Guiné e de Pai incognito, [...] Com Victoria $M^{a}$ da Crus, parda forra, $f^{a} n^{\text {al }}$ de Joana Glz, crioulla e de pay incognito, [...]." (Mattos 1996, 17-18).

Dois termos chamam a atenção nesta certidão: pardo(a) e crioulo(a). Entre outras possíveis significações, Frei Domingos Vieira, no Grande diccionario Portuguez, também as define como:

- Pardo: “Homem pardo; mulato" (Vieira (4) 1873, 662)

- Criôulo: Negro crioulo, negro nascido nas colonias, por opposição ao negro proveniente do trafico. (Vieira (2) 1873, 641)

Mais adiante, na sentença da sua petição de habilitação à carreira sacerdotal, o deão da Sé, dr. Francisco de Gomes Villas-Boas, registra que seus pais seriam "pardos, filhos de pretos" (Mattos 1996, 41).

Portanto, desta forma, tem-se que o pai de José Maurício seria um mulato alforriado, filho de uma preta escrava nativa da Guiné; sua mãe, uma mulata, também alforriada, cuja mãe seria uma preta escrava nascida no Brasil.

No entanto, outros autores não compartilham a mesma percepção, ou o fazem parcialmente, quanto ao mulatismo tanto de José Maurício Nunes Garcia, quanto ao de seus pais.

Organizado por Affonso de Escragnolle Taunay para as comemorações do primeiro centenário de morte do compositor, Uma grande glória brasileira: José Maurício Nunes Garcia reune os escritos do Visconde de Taunay publicados na imprensa do Rio de Janeiro entre 1859 e 1898, complementados pelo cotejamento com a biografia do compositor, escrita por Manuel de Araújo Porto-Alegre.

Esta publicação apresenta duas referências que chamam a atenção: na primeira, descreve tanto José Maurício quanto seus pais, respectivamente, como "homem de côr" ou "pessoas de côr" (Taunay [19-?]b, 55); na segunda, ao relatar a educação por ele recebida, registra-o como um "mulato quasi negro" (Taunay [19-?], 63).

Referência diversa pode ser inferida do livro Porque me ufano do meu paiz, do Conde Affonso Celso. Como o título indica, nesta publicação o seu autor enaltece as particularidades que o fazem ter orgulho do Brasil.

[...] 358. As testemunhas se inquiriraõ em fórma que concluaõ seus testemunhos, para prova de verdade, em semelhantes qualidades; \& depondo alguma testemunha de fama publica, ou commua (sic.) reputaçaõ de alguma nota, ou defeyto na qualidade do habilitando, declararà porque linha, \& parte lhe toca, \& se he descendencia de Judeos, Mouros, mulatos, ou hereges, ou de penitenciados, ou sambenitados pelo Santo Officio; \& a razaõ que há para ser o habilitando descendente da tal origem, \& a que pessoas o ouvio, \& em que tempo, \& lugar, \& o que sente em tal materia, \& se tem por verdadeyro, ou falso o tal defeyto, que se imputa ao habilitando (Regimento do Auditorio Ecclesiastico do Arcebispado da Bahia. Titulo VI - Do Juiz das justificaçoens de genere, \& a fórma que nellas deve guardar 1718, 94-95, grifo nosso).

Como se vê, era fundamental que o requerente tivesse limpeza de sangue, vida e costumes. Nesse processo, uma das maneiras de aferição dava-se por testemunhos, que, secretamente, atestariam a existência, ou não, de defeitos que impedissem que tal solicitação tivesse êxito. Entre as várias categorias de defeitos descritos, merece aqui atenção o de descendência, entre eles o defeito de cor. Assim, para ser nomeado padre, José Maurício Nunes Garcia foi dispensado do "defeito de cor", em 1792.

Se atentarmos que somente em janeiro de 1890, pelo Decreto no 119-A, ocorreu a regulamentação da liberdade de culto e a extinção do padroado, percebe-se o quanto tal concepção, frente aos não cristãos e mestiços, estava entranhada no tecido social nacional. 
Assim, entre os motivos apresentados, discorre sobre a grandeza territorial do país, a sua beleza natural, a sua riqueza, o seu clima e, entre outros, os "elementos que entraram na formação do typo nacional". Segundo Affonso Celso,

E' hoje verdade geralmente aceita que, para a formação do povo brazileiro, concorreram tres elementos: o selvagem americano, o negro africano e o portuguez.

Do cruzamento das tres raças resultou o mestiço que constitue mais de metade da nossa população.

Qualquer daquelles elementos, bem como o resultante delles, possue qualidades de que nos devemos ensoberbecer. Nenhum delles fez mal a humanidade ou a deprecia. (Celso 1901, 61)

Após essa apresentação do tema, cada elemento formador mereceu um capítulo especial: os índios, os negros, os portugueses e, por fim, os mestiços. Nessa publicação, chama a atenção que José Maurício Nunes Garcia esteja mencionado no capítulo destinado aos negros: “Que bella galeria de negros e filhos de negros illustres a que apresenta o Brazil! Eis José Mauricio Nunes Garcia, genio musical, amigo de D. João VI" (Celso 1901, 72. grifo nosso).

Ora, se o compositor era mulato, por que Affonso Celso não o apresenta no capítulo destinado aos mestiços? Qual a fonte que sustentaria a sua informação? A mesma questão vale quanto ao parecer fornecido pelo Visconde de Taunay - "mulato quasi negro".

Com essas questões, não teria sido José Maurício Nunes Garcia um compositor negro, pois filho de negros, retratado como mulato devido a teoria racial do branqueamento ${ }^{9}$ ?

Mesmo que considere José Maurício Nunes Garcia um compositor mulato, Marcelo Hazan apresenta uma significativa contribuição para o entendimento da recepção póstuma do compositor através da ênfase na "trajetória histórica percorrida pelo conceito de miscigenação" (Hazan 2009, 1). Se, a princípio, a mestiçagem representaria o atraso do país, a sua elevação à identidade nacional passaria antes pelo percalço do branqueamento, uma teoria de limpeza étnica em voga no Brasil na virada dos séculos XIX-XX, tendo em Manuel de Oliveira Lima um de seus representantes.

Ao discorrer sobre La musique au Brésil. Au point de vue historique, de Manuel de Oliveira Lima, trabalho apresentado pelo próprio autor no III Congresso da Sociedade Internacional de Música, em 1909, na cidade de Viena, Hazan demonstra a seriedade com que essa ideologia era considerada no Brasil. Segundo Hazan,

O branqueamento através da imigração era o objetivo precípuo da campanha propagandística à qual pertencia "La musique au Brésil". É da pena de Oliveira Lima (1899:52-53; apud Skidmore 1989 [1974]:88-89) a predição de que “a imigração <corrigirá a extrema mestiçagem estabelecida pelo português e firmará a real supremacia dos brancos' que ainda 'ameaçam [...] afundarse num alastramento de raças inferiores> (Hazan 2009, 33).

Observa-se nesta citação que, além de pregar o branqueamento, Manuel de Oliveira Lima também personificava a luta nacional contra os portugueses, o que não será aqui aprofundado.

\footnotetext{
${ }^{9}$ Ver Schwarcz, Lilia Moritz. 1993. O espetáculo das raças: cientistas, instituições e questão racial no Brasil, 1870-1930. São Paulo: Companhia das Letras.
} 
Quanto à ideologia racial do branqueamento, seu princípio já estava manifestado no verbete "Mulato" do Grande diccionario Portuguez, ou Thesouro da lingua Portugueza, de Frei Domingos Vieira:

Figurada e popularmente: O branco com a negra, ou vice-versa, produzem um mulato cuja côr é morena, isto é, mixta de preta e branca; este mulato com uma branca produz um segundo mulato menos moreno que o primeiro; e se este segundo mulato se unir do mesmo modo a um individuo de raça branca, o terceiro mulato não terá mais do que uma côr morena ligeira, que desapparecerá inteiramente nas gerações immediatas (Vieira (4) 1873, 351).

Logo, através da imigração branca europeia e não portuguesa, miscigenada aos mulatos nacionais, seria uma questão de tempo para que houvesse a purificação racial brasileira.

Assim, se de um lado temos uma ideologia que reconhecia a essência mestiça nacional, como atestado por Affonso Celso, por outro temos a sua negação, por considerar tal essência como nociva ao progresso e à civilização. Com isto, a representação de José Maurício como mulato atenderia às duas concepções: personificaria a essência mestiça nacional; apesar de mulato, já estaria branqueado culturalmente pois partilhava da grande cultura germânica.

Portanto, a imprecisão encontrada na descrição étnica de José Maurício Nunes Garcia - mulato, mulato quasi negro, negro - suscita questionamentos. Mesmo que a sua descrição como mulato tenha se tornado tradicional, encontrando repercussão, por exemplo, em Bruno Kiefer (1982), Vasco Mariz (2000), Marcelo Hazan (2009), Carlos Alberto Figueiredo (2012), a hipótese desse compositor ser negro e ter sofrido o filtro do branqueamento não deve ser descartada.

\section{Referências}

Appleby, David. 1983.The Music of Brazil. Austin: University of Texas Press.

Carvalho, Flávio. 2003.0 Nacional em Música na Obra de Alberto Nepomuceno. Rotunda, Campinas (2) 514.

Carvalho, José Murilo de. 1990. A formação das almas: o imaginário de República no Brasil. São Paulo: Companhia das Letras.

Celso, Affonso. 1901. Porque me ufano do meu paiz: right or wrong, my country. Rio de Janeiro: Laemmert.

Corrêa, Sérgio A. 1985. Alberto Nepomuceno Catálogo Geral. 1. ed.. Rio de Janeiro: Funarte.

Corrêa, Sérgio A. 1996. Alberto Nepomuceno Catálogo Geral. 2. ed.. Rio de Janeiro: Funarte.

Figueiredo, Carlos Alberto.2000. Editar José Maurício Nunes Garcia. Tese de Doutorado. Rio de Janeiro, Centro de Letras e Artes da UNIRIO.

Figueiredo, Carlos Alberto. 2012. “José Maurício Nunes Garcia”. In: Dicionario Biografico Caravelas. nov., 2012. Disponível em http://www.caravelas.com.pt/Jose Mauricio Nunes Garcia novembro 201 2.pdf, acessado em 03-01-2019.

Goldberg, L. G.; Nogueira, I. P. 2009. “Centro de Cultura Artística do Rio Grande do Sul: o início de um projeto ambicioso". In: Anais XIX Congresso da Associação Nacional de Pesquisa e Pós-Graduação. Curitiba: Edutora da UFPR. 
Hazan, Marcelo Campos. 2009. Raça, Nação e José Maurício Nunes Garcia. In: Resonancia (13) 24. 23-40. Jornal do Commercio, Rio de Janeiro, 7 out. 1895. Theatros e Música - Música Sacra. p. 2.

Jornal do Commercio, Rio de Janeiro, 2 abr. 1896. Theatros e Música - O Padre José Mauricio. p. 2.

Jornal do Commercio, Rio de Janeiro, 9 jan. 1897. Theatros e Música - Música Sacra. p. 2.

Jornal do Commercio, Rio de Janeiro, 24 jan. 1898. Theatros e Música - O Padre José Mauricio. p. 2.

Jornal do Commercio, Rio de Janeiro, 20 fev. 1898. Theatros e Música - Música Sacra. p. 2

Jornal do Commercio, Rio de Janeiro, 27 jun. 1898. Theatros e Música - Música Sacra - Padre José Mauricio. p. 3.

O Paiz, Rio de Janeiro, 25 fev. 1896. Artes e Artistas - O theatro. p. 2.

O Paiz, Rio de Janeiro, 4 mai. 1900. Quarto Centenario do Brazil - Evolução Artistica - A Musica I. p. 1-2

Kiefer, Bruno. 1982. História da Música Brasileira, dos primórdios ao início do séc. XX. 3a ed. Porto Alegre: Movimento.

Mariz, Vasco. 2000. História da música no Brasil. Rio de Janeiro: Nova Fronteira.

Mattos, Cleofe Person de. 1984. "Aparato crítico”. In: Garcia, José Maurício Nunes. Missa de Santa Cecília, 1826; para solistas, coro e grande orquestra. Rio de Janeiro: Funarte / INM / Pro-Memus, 7-32.

Mattos, Cleofe Person de. 1996. José Maurício Nunes Garcia: biografia. Rio de Janeiro: Fundação Biblioteca Nacional / Dep. Nacional do Livro.

Oliveira, Anderson José Machado de. 2008. "Suplicando a 'dispensa do defeito da cor': clero secular e estratégias de mobilidade social no Bispado do Rio de Janeiro - século XVIII. In: XIII Encontro de História Anpuh-Rio - Identidades. Rio de Janeiro: ANPUH. Disponível em http://encontro2 008.ri.anpuh.org/resources/content/anais/1212773302 ARQUIVO Texto-AndersondeOliveira-AnpuhRJ-2008.pdf, acesso em 09-01-2019.

Pequeno, Mercedes dos Reis. 1998. Impressão Musical no Brasil. In: Marcondes, Marcos Antônio (Org.). Enciclopédia da música brasileira: erudita, folclórica e popular. 2 ed., rev. ampl. São Paulo: Art Editora.

Pereira, Avelino R. S. 2007. Música, sociedade e política: Alberto Nepomuceno e a República Musical. Rio de Janeiro: Editora UFRJ.

Picard, Timothée (org.). 2010. Dictionnaire Encyclopédique Wagner. Paris: Actes Sud, Cité de la Musique.

Porto-Alegre, Manuel de Araújo. 1856. Apontamentos sobre a vida e a obra de José Maurício Nunes Garcia. In: Revista do Instituto Histórico e Geográfico Brasileiro 19. Rio de Janeiro: Imprensa Nacional, 354369.

Regimento do Auditorio Ecclesiastico do Arcebispado da Bahia. Lisboa: Pascoal da Sylva, 1718.

Reis, José Carlos. 2002. As Identidades do Brasil: de Varnhagen a FHC. 5 ed. Rio de Janeiro: Editora FGV.

Sacramento BLAKE, Augusto Victorino Alves. 1899. "José Maurício Nunes Garcia". In: Diccionario Bibliographico Brazileiro. v. 5. Rio de Janeiro: Imprensa Nacional.

Taunay, Visconde de. [19-?]-a. Dous artistas máximos: José Maurício e Carlos Gomes. São Paulo: Melhoramentos. 
Taunay, Visconde de. [19-?]-b. Uma grande glória brasileira: José Maurício Nunes Garcia. São Paulo: Melhoramentos.

Vermes, Mónica. 2000. "Alguns aspectos da música sacra no Rio de Janeiro no final do século XIX". Revista Eletrônica de Musicologia 5 (1). Disponível em http://www.rem.ufpr.br/ REM/REMv5.1/vol51/rio.htm, acesso em 28-12-2009.

Vermes, Mónica. 2004. "Por uma renovação do ambiente musical brasileiro: o relatório de Leopoldo Miguez sobre os conservatórios europeus". Revista Eletrônica de Musicologia 8 (2). Disponível em http://www.rem.ufpr.br/ REM/REMv8/miguez.html, acesso em 28-12-2009.

Vieira, Frei Domingos. 1873. Grande diccionario Portuguez ou Thesouro da lingua Portugueza. Porto: Ernesto Chardron\&Bartholomeu H. de Moraes. 